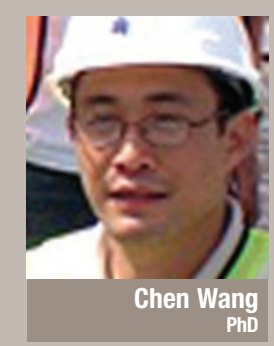

is a senior research fellow at the centre for construction innovation and project management at the University of Malaya

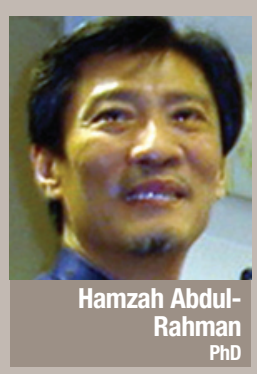

is a professor at the centre for construction innovation and project management at the University of Malaya

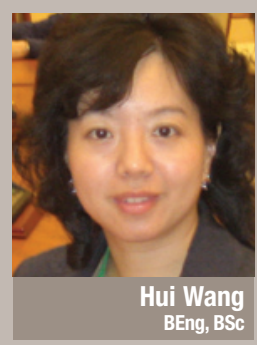

is general manager assistant at China Construction First Division Group Construction \& Development

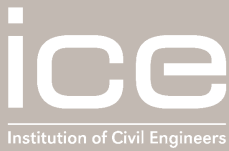

\section{Delivering the Beijing National Aquatics Center}

\author{
The Beijing National Aquatics Center played a key role in the 2008 \\ Olympics. It was a ground-breaking project in many ways, with its \\ highly complex and irregular polyhedron steel space frame clad \\ with ethylene tetrafluoroethylene membrane pillows - designed \\ to resemble a 'water cube' - setting new standards for design and \\ construction technology. This paper provides an overview of the \\ innovative design and explains how the concept of 'on-site further \\ design' was formally developed to help deliver it.
}

The Beijing National Aquatics Center was one of the two main venues for the 2008 Beijing Olympic Games (Chen et al., 2008; Yuan et al., 2008) (Figure 1). By adopting a completely novel structural form and innovative building materials it broke the mould of traditional steel and concrete building design.

Details of the venue are listed in Table 1 and the layout is shown in Figure 2. It was the first time Lord Kelvin's foam bubble theory was applied in architecture and is also the world's largest public building wholly enclosed by an ethylene tetrafluoroethylene (ETFE) air-filled membrane (Yuan et al., 2008).

The main challenge for the contractor, China State Construction Engineering
Corporation, was how to manage the combined application of an irregular polyhedron steel space frame with an inflated ETFE membrane. This led to the formal development of the concept of 'on-site further design' by the contracting team.

\section{Bubble theory and steel structures}

At the end of the nineteenth century, UK physicist William Thomson (later Lord Kelvin) put forward a foam bubble theory to investigate how space could be partitioned in cells of equal volume with the least area of surface between them (Thompson, 1887). His proposed solution was a tetradecahedron - a 14 sided polyhedron - with six square faces and eight hex-
Table 1. Facts and figures on the Beifing National Aquatic Center

\begin{tabular}{ll|} 
Construction cost & $£ 98$ million \\
Overall floor area & $79532 \mathrm{~m}^{2}$ \\
Number of permanent seats & 6000 (2000 removable) \\
Number of temporary seats & II 000 \\
Construction start date & 24 December 2003 \\
Construction completion date & 28 January 2008 \\
Designers & PTW Architects, Arup and China Construction Design International \\
Main contractor & China State Construction Engineering Corporation \\
\hline
\end{tabular}




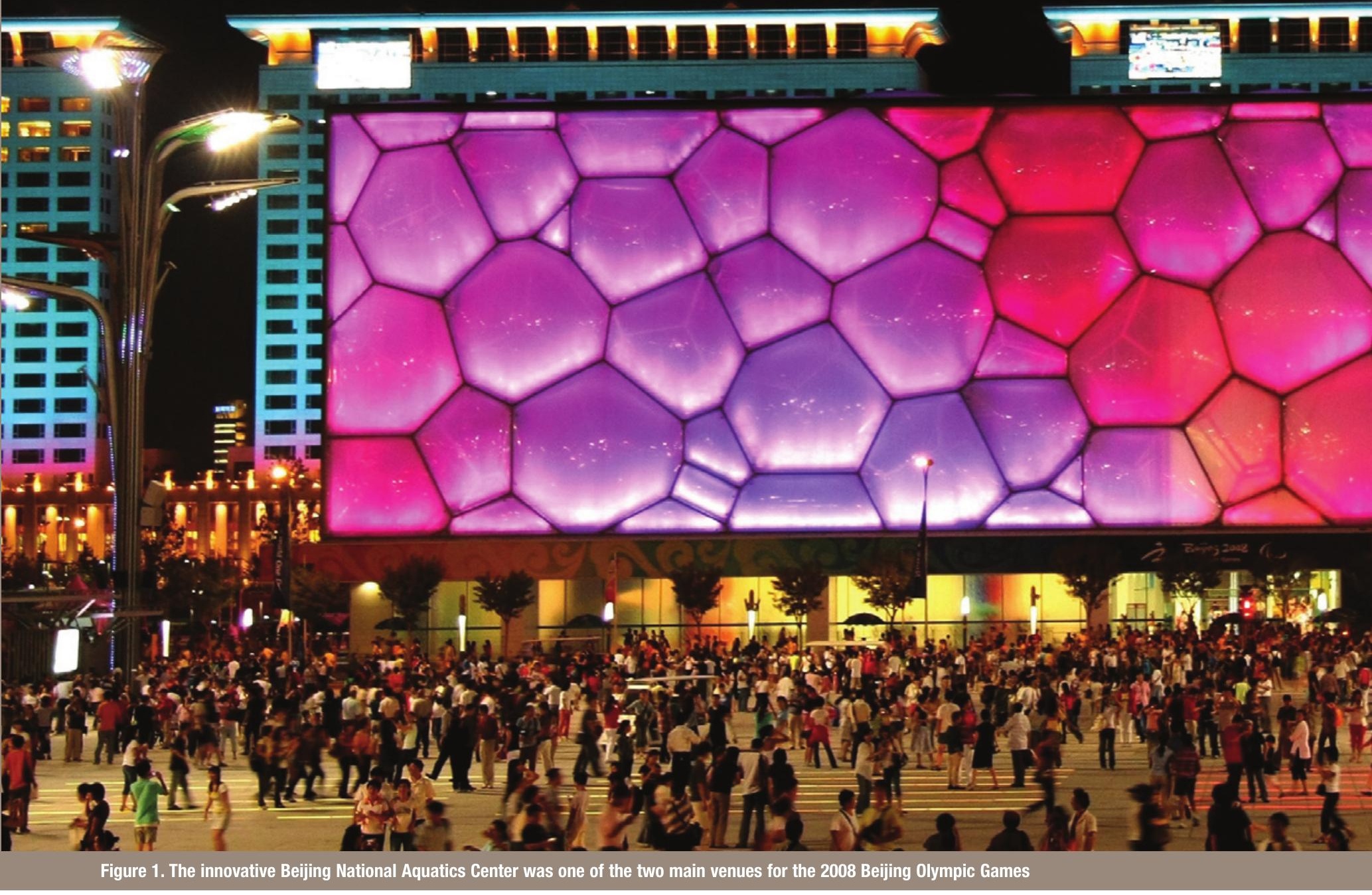

It was the first time Lord Kelvin's foam bubble theory was applied in architecture

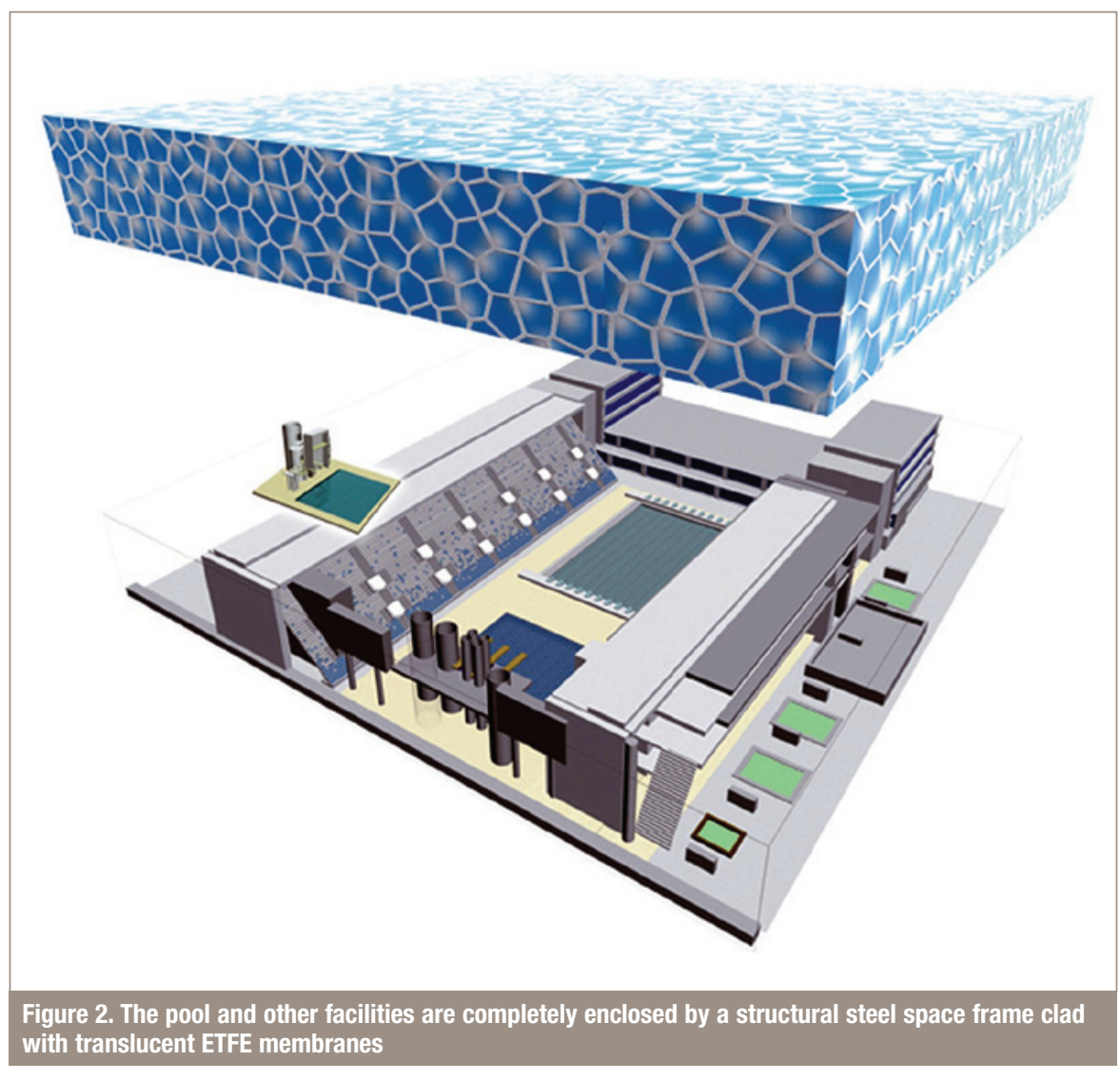




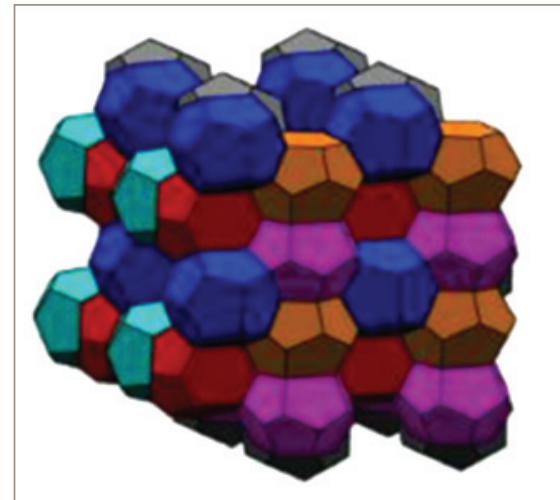

Figure 3. William Thomson's bubble model consisted of tetradecahedrons with eight hexagonal faces and six square faces

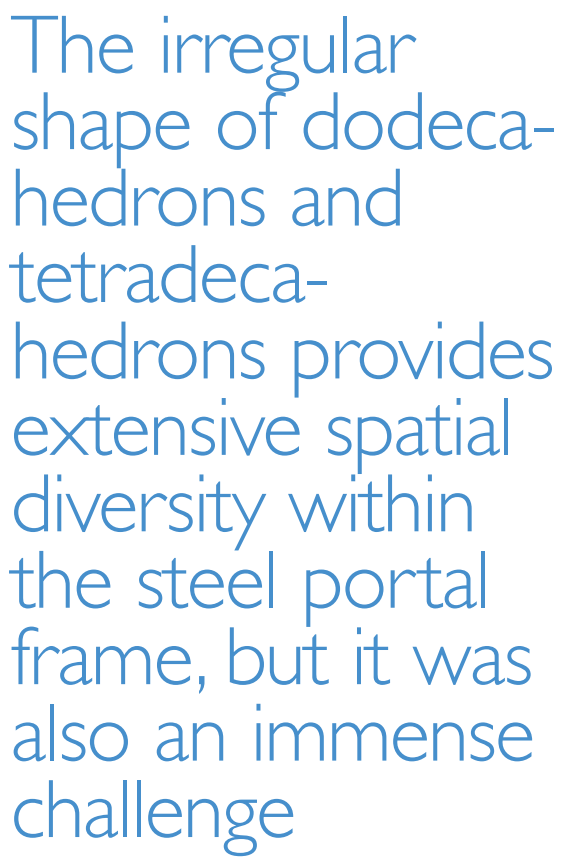

agonal faces (Figure 3) (Chen et al., 2008; Robinson, 2005; Zhang and Qin, 2007).

It was not until 1993 that professors at Trinity College, Dublin - Denis Weaire and Robert Phelan - suggested an improvement, grouping six tetradecahedrons, with two hexagonal faces and 12 pentagonal faces, around an irregular dodecahedron, with 12 pentagonal faces (Weaire and Phelan, 1994). It was this configuration that provided the inspiration for the National Aquatics Center's structural steelwork design (Figure 4) (Chen et al., 2008; Yuan et al., 2008).

The polyhedron steel space frame which forms the roof and wall structures of the venue is the first of its kind in building history (Yuan et al., 2008; Zheng and Zhang, 2008). The irregular shape of dodecahedrons and tetradecahedrons provides extensive spatial diversity within the steel portal frame, but it was also an immense challenge to those responsible for manufacturing, installing and welding the many thousands of constituent parts. Such a complex and large project requires a highly experienced construction management team.

\section{Using ETFE as a membrane}

ETFE is a colourless and transparent crystalline material (Becker and SchmidtNaake, 2001; He and Hoyano, 2010; Luo et al., 2006; Robinson, 2005), and an ETFE membrane is a non-fabric sheet extruded from the raw material. It is currently the most advanced construction membrane in the world.

ETFE membranes were initially developed by Nasa for use in its space programme. They were first applied in construction by Foiltec Germany in 1982 (Becker and Schmidt-Naake, 2001; Luo, et al., 2006; Robinson, 2005; RobinsonGayle et al., 2001; Saarinen et al., 2006).

The many advantages of this kind of membrane include very low weight, long life, resistance to stretching, elasticity, resistance to ultraviolet radiation and chemicals, self-cleaning and non-flammability (Hinz et al., 2009; Robinson, 2005; Saarinen et al., 2006; Wyckmans, 2005).

ETFE membrane cladding systems are architecturally translucent and highly aesthetic. Requiring only lightweight support structures, they also have low environmental impact and are energy efficient (Ando et al., 1999; Shi, 2008). Roofs and walls made of ETFE membranes are around $10 \%$ of the weight of similar thickness glass.

However, ETFE membranes have not been widely adopted due complexities in their design, installation and maintenance (Bonet et al., 2000; Gluck et al., 2001; Li and Chan, 2004; Wu and Ting, 2008). Well-known projects using the material on a smaller scale include this Eden Project in the UK and the Allianz Arena in Germany (Robinson-Gayle et al., 2001; Wyckmans, 2005).

The National Aquatics Center is currently the largest ETFE-enveloped construction project in the world. The inner and outer surfaces - a total of $100000 \mathrm{~m}^{2}$ - of the structural frame are clad with over 3000 air-filled ETFE cushions with $0 \cdot 2 \mathrm{~mm}$ wall thickness (see Figure 5).

The great challenges for design and construction include the adaptability of ETFE and internal building environment issues such as ventilation, air conditioning, fire prevention, sound, lighting

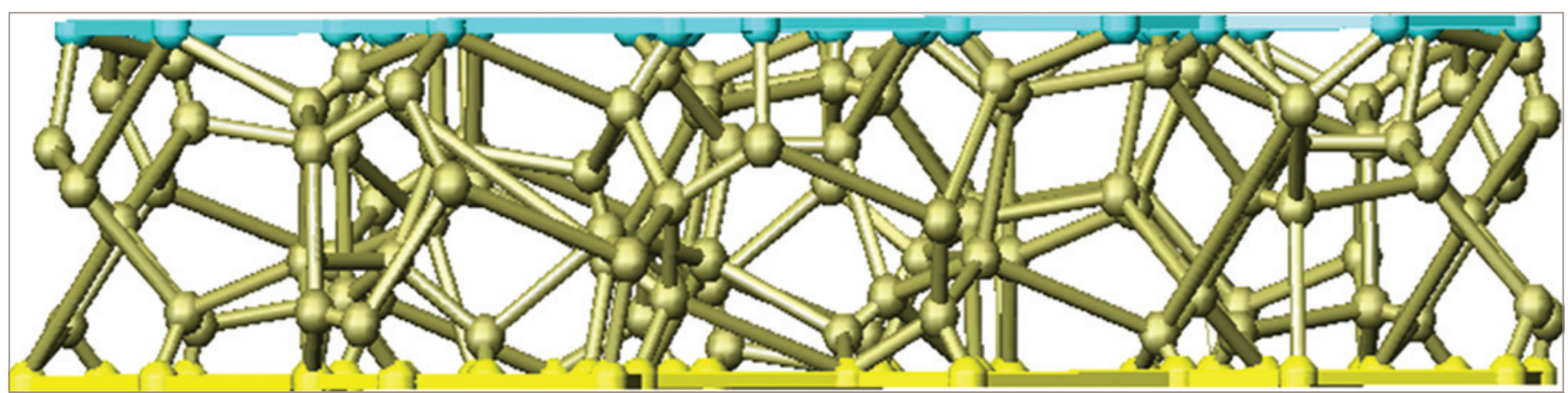

Figure 4. The 'bar and ball' steel space frame used for the Beijing National Aquatics Center roof and walls is effectively a slice through a Weaire-Phelan bubble model, based on a repeating pattern of six tetradecahedrons with one dodecahdron 
and heating (Chen et al., 2008; He and Hoyano, 2009; Shi, 2008; Zhang and Qin, 2007).

\section{On-site further design}

The concept of on-site further design was proposed and developed by the contracting team of the National Aquatics Center project. It is a vital technique for projects which feature unique design concepts and/or complex construction technologies.

In the case of the National Aquatics Center, the drawings provided by the designers could not be used directly as construction details, so a large amount of further design and design optimisation was carried out by the contracting team. Further design was conducted for the steel structures, membrane structures, mechanical and electric installation and finishes.

To realise the design on site to maximum effect, the contracting team encouraged mutual support among all subcontractors and suppliers and provided a platform for technology sharing during the further design procedure.

On-site further design includes the following processes

technology and resource preparation development of new standards and codes

further design of structures

- preliminary trials for key elements

- further design of quality-control systems.

The processes are set out in a flow chart in Figure 6.

\section{Application in Beijing}

\section{Technology and resource preparation}

The National Aquatics Center project used a large amount of Q420C (GB) steel, characterised by high carbon content and high cold-cracking sensitivity, equivalent to S420NL (BS/BSEN) in British standards (Brockenbrough, 2006). Its welding parameters under constant temperature and negative temperature include current, voltage, preheating before welding, interlayer temperature and thermal insulation after welding.
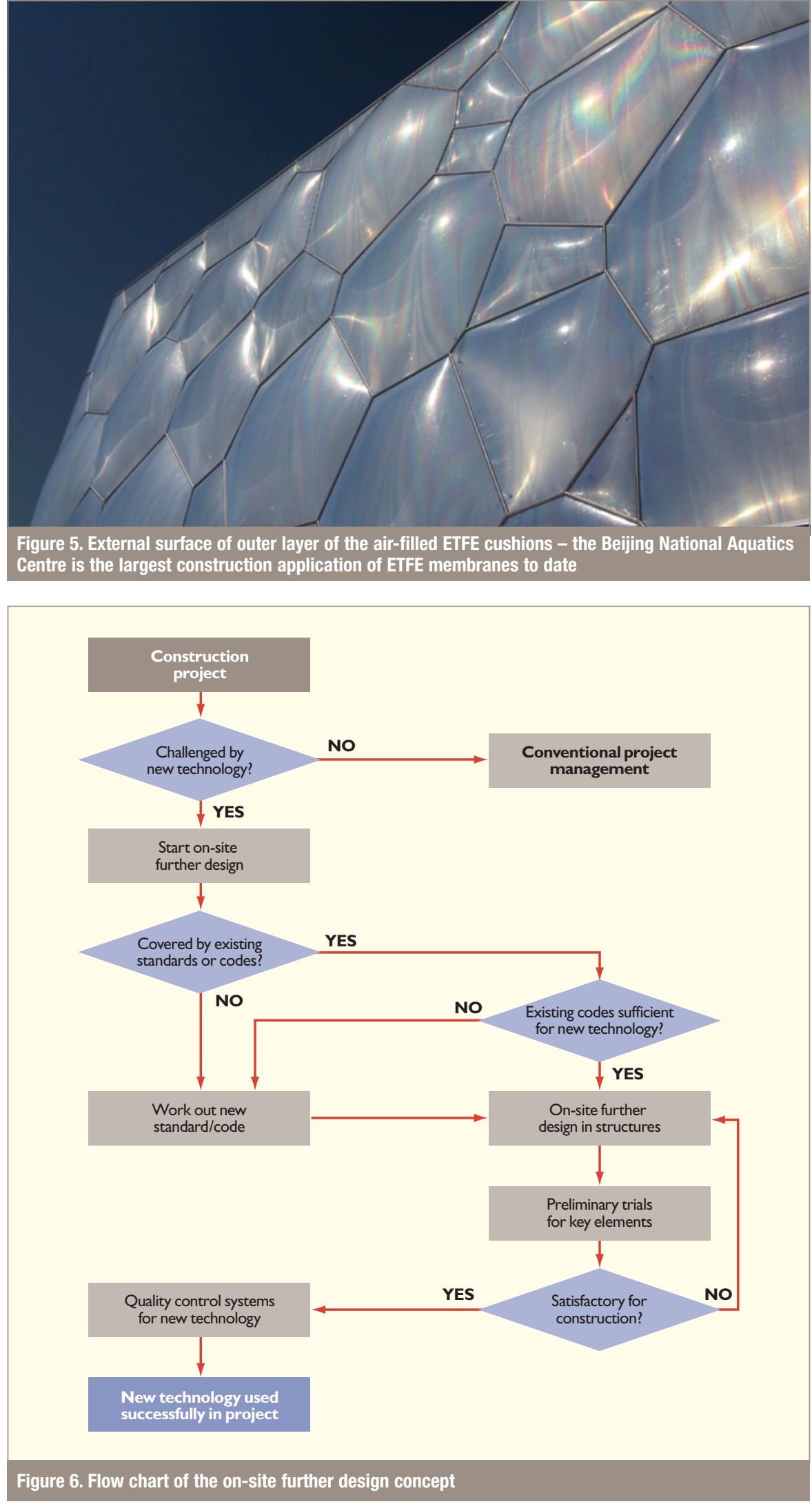
However, Chinese national standards at the time did not refer to those welding parameters.

The contracting team therefore carried out a series of tests to explore the specific technical parameters for the steel. They then produced a quality standard for evaluating the welding technology for Q420C steel sheet, which established the foundation for using the material on the project.

Furthermore, in coordination with architectural and national scientific research institutions, the contracting team conducted a 1-year test on weather resistance, vision, acoustics, optics and thermal performance of ETFE membranes - both in the laboratory and on site - to ensure the material would meet the functional requirements of a swimming pool.

The contracting team redeveloped various design parameters - such as membrane thickness, density of the reflective plating spots, layers of membrane material and form of aluminum alloy support frame - to establish a sound basis for using ETFE on the project.

\section{Development of new standards and codes}

The roof and the walls of National Aquatics Center were combined into a single polyhedron space frame. Because this kind of combination was the first application at both a national and international level, there were no construction standards or projects to refer to.

Assisted by experienced technicians,
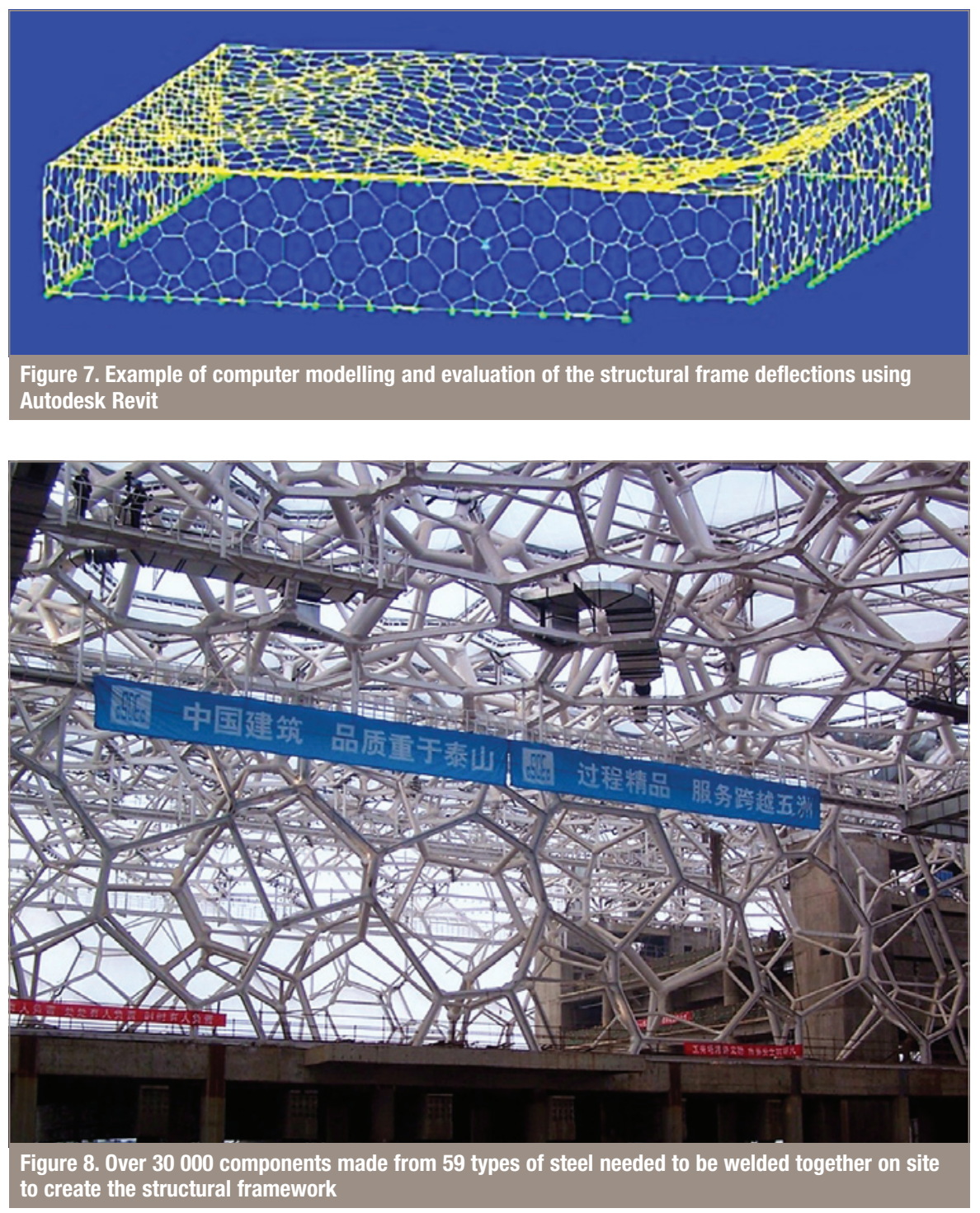

the contracting team developed a document called 'Acceptance Regulations on Construction Quality of the Main Steel Structure Works of National Aquatics Center, which provides guidance on the improvement of national codes for Olympic construction projects.

Furthermore, as the venue was the first project using ETFE membrane material in China, there was no corresponding standard or regulation at that time. Collaborating with national scientific research institutes and professionals, the contracting team also developed 'Acceptance Standard for Technical and Construction Quality of the Roof and Wall ETFE Assembly System Works of National Aquatics Center', providing specific requirements on material, design, manufacturing, installation, repair and maintenance for the membrane cladding.

\section{Further design of structures}

Creating the structural arrangement based on repeating patterns of six tetradecahedrons plus two dodecahedrons required more than 30000 steel members and spherical nodes to be assembled into thousands of irregular polyhedrons. This required a large amount of computer modelling and further design before construction. Aided by its headquarters technical support team, the contracting team simulated and analysed the stress and distortion of the steel structure under various construction and loading conditions (Figure 7).

Over 200 design drawings were developed into more than 2000 detailed drawings and then into approximately 30000 member fabrication drawings.

The steel structure of the National Aquatics Center required many types of steel to achieve the various structural and architectural requirements. A total of 59 types of steel with different strengths and specifications were used, including several high-strength versions that created challenges in manufacture (Figure 8). Aided by the modelling results, quantity surveying staff were able precisely to estimate the quantity of each type of steel required, thus keeping costs under control.

The 3216 pneumatic ETFE cushions used to clad the outer and inner sides of the steel frames had many different shapes. The largest span of an individual cushion 
was $11 \mathrm{~m}$, more than the manufactured width of ETFE membranes, so larger cushions were assembled from several membranes welded together. To ensure the exterior appearance of the building, the contracting team optimised the connecting seams of the pneumatic cushions so they ran on the same line from the top to the bottom of the building.

The contracting team then organised technical personnel and subcontractors to determine the physical dimensions of each ETFE cushion in order to produce fabrication drawings. Many cushions had angular spaces between them, so the support framework was made adjustable in three dimensions to mitigate installation issues. A 'bubble bar' was formed on the southeast corner of the second floor, embedded with self-locking, multiple waterproof and sealed structures (Figure 9). After a 1-year test under various weather conditions, no leakage was detected in the roof or walls.

Figure 10 shows part of the outer membrane during installation.

\section{Preliminary trials for key elements}

Preliminary trials were conducted for procuring and assembling key elements such as the steel structure, the membrane structure and the swimming pool.

For example, the Q345C and Q420C high-strength steel had not been massproduced in China before, so the steel plants needed to undertake production trials. The contracting team and the steel manufacturers then conducted hundreds of experiments on the $250 \mathrm{t}$ of steel produced in the trials.

The preliminary preparations for the steel structure included clarifying the overall arrangement, preparing for procurement, selecting processing plants, purchasing of construction equipment, developing the construction programme, training welders, leaving sufficient time for technical research and testing the steel structure. All this helped to ensure on-time completion of the work.

The welding seams on the steel structure were required to be top grade, so the welders all had to hold 6GR (all-position welding) certificates. The contracting team organised more than 1000 welders to attend technical training and to sit for the 6GR examination.
From those who passed, only around 250 qualified welders with more than 5 years' welding experience were selected for the welding operations.

To understand the installation characteristics of ETFE cushions further, the contracting team together with subcontractors carried out a trial installation before construction. A full-scale steel frame model was built on which 15 pneumatic cushions could be installed to simulate the installation of sub-structures such as the suspended ceiling and cushion-support system. The contracting team also used the model to provide installation training for construction personnel.

As the membrane structure was the first to be used in China, the contracting team also organised senior personnel to receive technical training in Germany. To control construction quality of the ETFE membrane structure from the outset, the contracting team conducted process monitoring throughout construction.

The swimming pool was another key element of the project. The contracting pool as well as the facilities installation. For instance, the team simulated and arranged tile layouts in advance and determined the structural dimensions of each part according to tile thickness. All reserved and inbuilt parts of the pool team preplanned the finishing of the
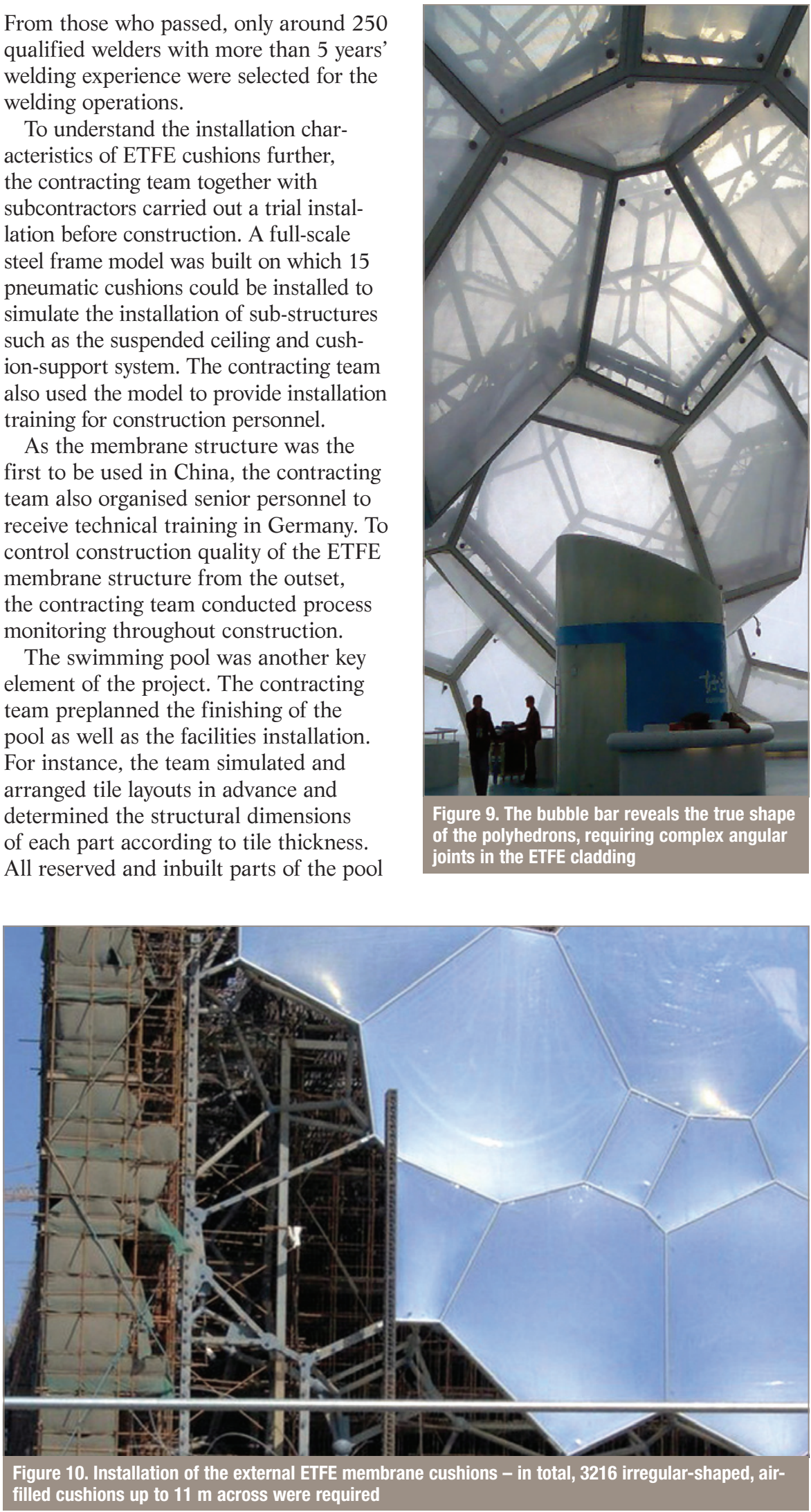
structure were preplanned by computer before concreting to ensure subsequent construction activities were not delayed.

Experiments were also conducted using full-scale models to ensure that the tiles and various intergral parts were combined correctly and accurately. The tiling precision in the swimming pool exceeded the requirements of the International Swimming Federation (see Figure 11).

Further design and quality control systems The innovative polyhedron space frame was welded from 20670 steel members and 9843 spherical steel nodes. The contracting team had to overcome the challenges of member fabrication, installation, temporary support, strict standards for welding and a tight timescale.

Three-dimensional positioning of each member was needed. The contracting team independently developed a computer system entitled Fast Three-Dimensional Space Positioning Measurement System for use on the project. This not only ensured precise positioning but also accelerated construction.

A programme called Single Bar Plus Single Ball Ground Assembly And High-Altitude Installation System was also developed for the space frame construction. In developing this system, the contracting team conducted various experiments, including welding Q420C steel materials under constant temperature and negative temperature, steel preheating, interlayer temperature control in welding, temperature measurement and paired-bars welding technology. The team also devised a quality standard for evaluation of welding technology.
The in situ assembly of each 'bar and ball' also required a flexible access platform system, which could be quickly moved into position and attached to the structure as required. During construction, the roof and wall scaffolds were set up and removed several times before installation went smoothly.

In addition, to monitor the stress changes caused during progressive installation of the steel structure, the whole installation process was monitored by a system developed by the contracting team. The results showed that the stresses in members were less than the designed values.

During installation of the ETFE cushions, the contracting team developed a further programme called the ETFE Membrane Structure Assembly System. Aided by this system, the contracting

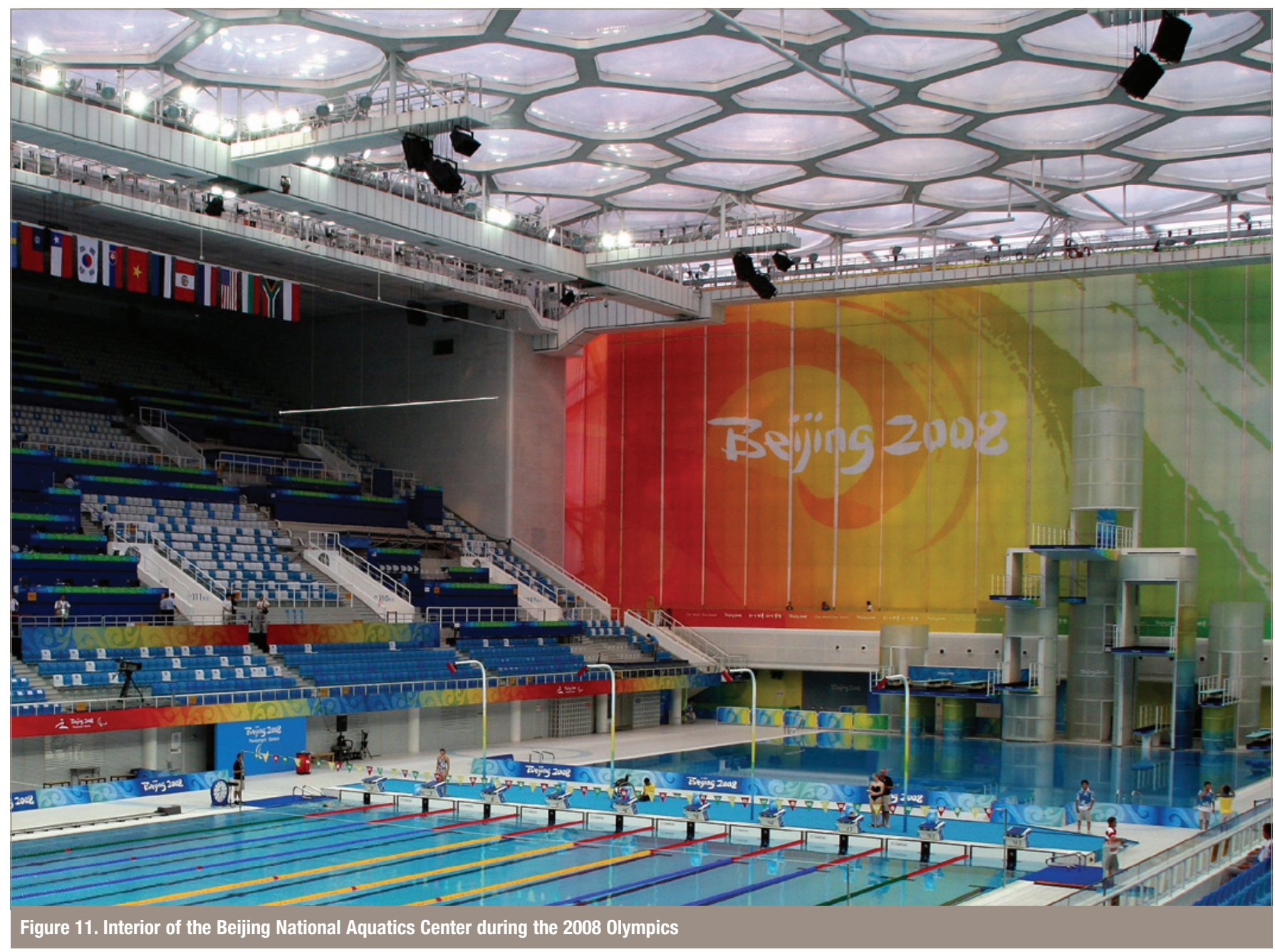


team pre-inflated the cushions to 10 times working pressure in a shape-testing rig to ensure air-tightness and shape.

The contractor introduced the world's largest straight-line welding equipment for joining and sealing for the membranes. Due to the complex shape and size of the cushions, wrinkle-elimination methods were needed such as ironing and air-pressure adjustments.

On the internal membranes of the external cushions and the external membranes of internal cushions, hundreds of millions of small reflective plates were attached to reduce solar gain and improve thermal insulation.

\section{Critical review of limitations}

The new technologies managed using the on-site further design concept on the Beijing National Acquatics Center, such as the polyhedron steel space frame and ETFE membrane structures, were limited to structural engineering. Further research is needed to assess the application of the concept for new technologies in other fields such as electrical engineering, electronic engineering and air conditioning.

Also, the concept as developed does not cover the consideration of issues such as preventing corrosion and further maintenance of steel. While it was successful on the Beijing National Aquatics Center, it needs to be tested on other projects to verify its potential for universal application.

Further work is also needed to refine and enhance the concept processes and procedures.

\section{Conclusion}

The new-technology challenges on the Beijing National Aquatics Center project were successfully managed by the contracting team through the development of an on-site further design concept.

The concept provided valuable guidance and standards for future large-scale applications of polyhedron steel structures and ETFE cushions in sport facilities and stadia.

For a complicated, low-repeat, irregular steel structure such as that used on the Beijing National Aquatics Center, the contracting team effectively reduced component types in the original design through on-site further design and also eased the difficulties in procurement and site installation, optimised welding procedures, improved work efficiency, and provided a strong guarantee for overall structural safety.

Through the following five processes, namely

technology and resource preparation

development of new standards and codes further design of structures

- preliminary trials for key elements

further design of quality-control systems

the on-site further design concept effectively managed the new-technology challenge on this innovative construction project.

The authors recommend that the procedure is developed and tested for universal application in other construction projects confronting new-technology challenges.

\section{References}

Ando K, Ishii A, Suzuki T, Masuda K and Saito Y (1999) Design and construction of a double membrane airsupported structure. Engineering Structures 2I(8): 786-794.

Becker W and Schmidt-Naake G (200I) Properties of polymer exchange membranes from irradiation introduced graft polymerization. Chemical Engineering \& Technology 24(II): II28-II32.

Bonet J, Wood RD, Mahaney J and Heywood P (2000) Finite element analysis of air supported membrane structures. Computer Methods in Applied Mechanics and Engineering I90(5): 579-595.

Brockenbrough RL (2006) Structural Steel Designer's Handbook: AISC, AASHTO, AISI, ASTM, AREMA, and ASCE-07 Design Standards. McGraw-Hill, New York, NY, USA.

Chen XM, Zhao ZX and Zhang X (2008) Application of ETFE membrane structure on national aquatics center (water cube). Architecture Technology 39(3): 195-198.

Gluck M, Breuer M, Durst F, Halfmann A and Rank E (200I) Computation of fluid-structure interaction on lightweight structures. Journal of Wind Engineering and Industrial Aerodynamics 89(14): I35I-I368.

$\mathrm{He} J$ and Hoyano A (2009) Measurement and simulation of the thermal environment in the built space under a membrane structure. Building and Environment 44(6): III9-II27.

$\mathrm{He} \mathrm{J}$ and Hoyano A (2010). Measurement and evaluation of the summer microclimate in the semi-enclosed space under a membrane structure. Building and Environment 45(I): 230-242.

Hinz S, Stephani M, Schiemann L and Zeller K (2009) An image engineering system for the inspection of transparent construction materials. ISPRS Journal of Photogrammetry and Remote Sensing 64(3): 297-307.

$\mathrm{Li} \mathrm{JJ} \mathrm{and} \mathrm{Chan} \mathrm{SL} \mathrm{(2004)} \mathrm{An} \mathrm{integrated} \mathrm{analysis} \mathrm{of} \mathrm{membrane} \mathrm{structures} \mathrm{with} \mathrm{flexible} \mathrm{supporting} \mathrm{frames.}$ Finite Elements in Analysis and Design 40(5): 529-540.

Luo Y, Xu X, ji W et al. (2006) Arranging the plastic hinges and improving the strength of steel tubes with tapered ends: analysis and tests. Journal of Constructional Steel Research 62(9): 885-892.

Robinson LA (2005) Structural Opportunities of ETFE (ethylene tetra fluoro ethylene). MEng thesis, Massachusetts Institute of Technology, Cambridge, MA, USA.

Robinson-Gayle S, Kolokotroni M, Cripps A and Tanno S (200I) ETFE foil cushions in roofs and atria. Construction and Building Materials I5(7): 323-327.

Saarinen V, Karesoja M, Kallio T, Paronen M and Kontturi K (2006) Characterization of the novel ETFEbased membrane. Journal of Membrane Science 280(I): 20-28.

Shi HB (2008) "Water Cube" and technology Olympics room acoustics design for the National Aquatics Center. Entertainment Technology, 4(2008): 12-18.

Thompson W (I887) On the division of space with minimum partitional area. Philosophical Magazine 24(I5I): 503-5I4.

Weaire D and Phelan R (1994) A counterexample to Kelvin's conjecture on minimal surfaces. Philosophical Magazine Letters 69(2): 107-II0.

Wu TY and Ting EC (2008) Large deflection analysis of 3D membrane structures by a 4-node quadrilateral intrinsic element. Thin-Walled Structures 46(3): 26I-275.

Wyckmans A (2005) Intelligent Building Envelopes: Architectural Concept \& Applications for Daylighting Quality. $\mathrm{PhD}$ thesis, Norwegian University of Science and Technology, Trondheim, Norway.

Yuan JF, Yu LS and Wang Y (2008) Construction technology for ETFE membrane structure in national aquatics center (water cube). Architecture Technology 39(3): 184-194.

Zhang SL and Qin CL (2007) Technical essentials and implementation of measurement in structural construction of National Aquatics Center (water cube). Engineering Survey I0(2007), doi: CNKI:SUN:GCKC.0.2007-10-013

Zheng F and Zhang X (2008) The water cube: National Aquatics Center. Architectural Journal 6(2008): 36-47. 